\title{
Mortality from early onset group B streptococcal infection in the United Kingdom
}

\author{
Nick Embleton, Unni Wariyar, Edmund Hey
}

\begin{abstract}
Aims-To assess the assumption that group B streptococcal infection is less common in the United Kingdom than it is in the United States.

Methods-All stillbirth and neonatal death records in the former Northern Health Region were scrutinised to determine how many babies had died of infection in 1981-96, and what had been the cause.

Results-Fifty one of 630206 live born babies had died of confirmed group $B$ streptococcal infection after becoming symptomatic within 48 hours of birth $(0.8$ neonatal deaths per 10000 live births). There were a further 27 deaths from infection without a confirmed microbiological diagnosis, and 17 stillbirths from confirmed group B streptococcal infection.

Conclusions-The incidence of death from early onset infection was marginally higher than the officially estimated rate for the United States before widespread prophylaxis was attempted. Strategies for perinatal prevention deserve greater attention in the United Kingdom.

(Arch Dis Child Fetal Neonatal Ed 1999;80:F139-F141)
\end{abstract}

Keywords: group B streptococcal infection; congenital infection; perinatal death

Group B streptococcal infection has been the most common cause of severe, early onset neonatal infection in much of the developed world over the past three decades. It does not, however, seem to be responsible for more than $2 \%$ of diagnosed neonatal sepsis in Africa, India, the Middle East or South East Asia. ${ }^{1}$ More recently in the United States it has been seen as a major, potentially preventable, cause of perinatal death. ${ }^{2}$ Guidelines on prevention have been published by various professional bodies $^{3-5}$ and widely adopted in the United States and parts of Australia. ${ }^{6}$

Whether group B streptococcus is a major cause of sepsis or death in this country (and the rest of Europe) is less clear. The only previous large scale population based study in this country was carried out 20 years ago by the Public Health Laboratory Service, but was unfortunately only published in symposium format. ${ }^{7}$ We present the incidence of death due to early onset group B streptococcal infection from a large, geographically defined United Kingdom population and compare it with other large studies from Europe, the United States and Australasia.

\section{Methods}

The former northern health region covers a population of 3.1 million people, and has tightly defined geographical borders with few cross border referrals. Cases were identified using data for the years 1981-96 held by the Northern Region's Perinatal Mortality Survey. ${ }^{8}$ The records in this large well validated database contain carefully cross audited information on cause of death, but the obstetric, paediatric, and pathology case notes of the 301 non-malformed infants classified as dying from infection within 28 days of birth were all reviewed afresh during the course of this study. Cases were defined as early onset where there was clear documented evidence of symptoms compatible with group B streptococcal infection in the first 48 hours of life.

During the 16 years there was no policy for the routine screening of maternal group B streptococcal carriage, and no widespread policy of prevention using intrapartum antibiotic prophylaxis.

\section{Results}

There were 630206 live births during the study and 51 deaths in babies with confirmed early onset group B streptococcal infection. The clinical course in all the babies was compatible with a diagnosis of severe sepsis. In 37 cases the diagnosis was made on the basis of a positive deep culture: blood $(n=26)$, blood and cerebrospinal fluid $(n=3)$, blood and tracheal aspirate $(n=7)$, or tracheal aspirate $(\mathrm{n}=1)$. In 11 cases group B streptococci were isolated at necropsy and there was histopathological evidence of infection, but no cultures had been taken $(n=7)$ or organisms isolated $(n=4)$ during life. In two cases where no deep cultures were performed group B streptococci were isolated on superficial swabs (one of whom had pneumonia confirmed at necropsy but with no microbiological evidence), and in one case blood cultures were negative, no necropsy was performed, but group B streptococci were isolated from superficial swabs.

Another 27 babies had strong clinical evidence of infection in the first 48 hours, but no satisfactory microbiological diagnosis. Features of infection were present in all 21 who came to necropsy. Many of these babies had probably also died from group B streptococcal infection. Eight were born to mothers colonised with the organism, and in a further four, antibiotics had been given before delivery. No cultures were ever obtained from the mother or baby in a further seven cases.

Another 23 babies of 20 or more weeks gestation were born dead between 1987-96 with overt maternal group B streptococcal sepsis or 


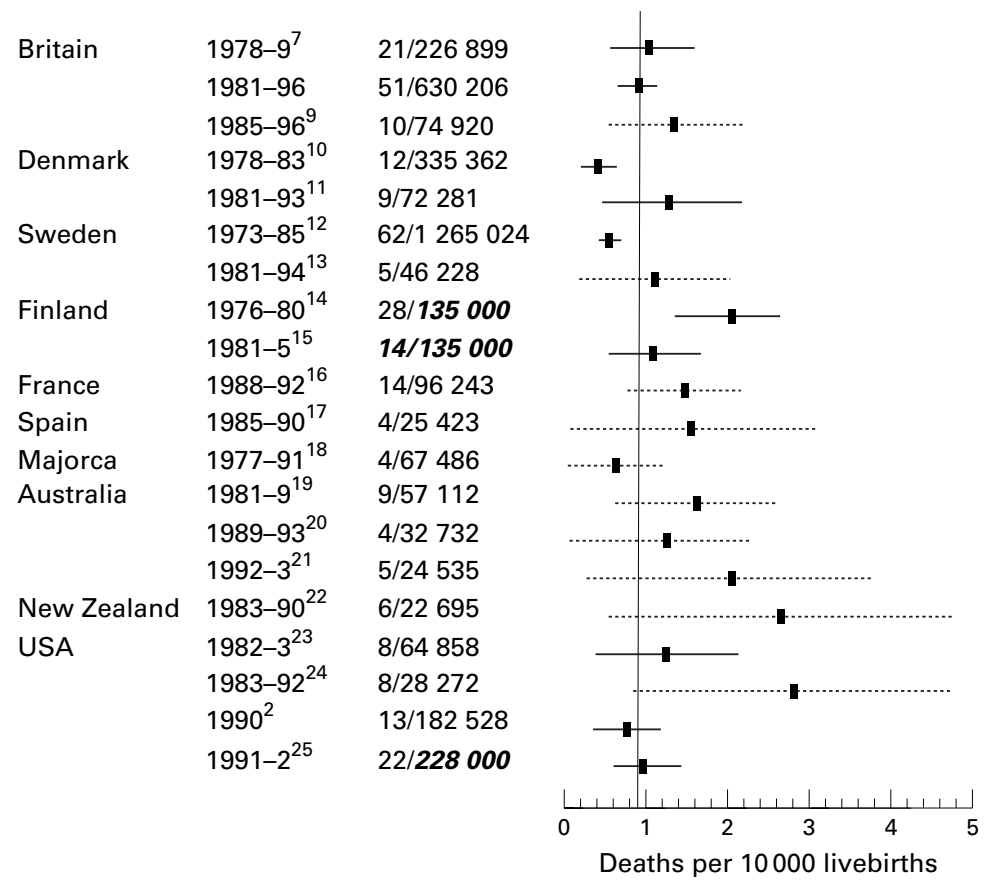

Figure 1 Prevalence of neonatal death from early onset group B streptococcal infection (studies involving at least 20000 births only). The black bars show the 95\% confidence intervals for population based studies, and the hatched bars the confidence intervals for other (potentially less representative) hospital based studies. Denominator figures in bold italics are estimates; the enumerator figure in bold italics is calculated from the stated rate. The vertical line is the average for population based studies.

necropsy evidence of group B streptococcal infection; 17 of these were 24 or more weeks gestation at delivery (median gestation 32 weeks) and would, therefore, now be classified as stillborn. Seven of these died during labour.

Of the 51 confirmed neonatal deaths, 33 $(66 \%)$ were symptomatic at birth and 49 (96\%) symptomatic by 18 hours. Median birthweight was $1770 \mathrm{~g}$ (range 520-4740 g), median gestation 31 weeks (range 24-41 weeks), and median age of death 18 hours (range 1 hour to 9 days). Ten mothers were delivered at term (37-41 weeks gestation): only four had ruptured membranes for more than 24 hours before delivery, and none had a recorded intrapartum temperature of more than $37.5^{\circ} \mathrm{C}$. In only $5 / 51$ cases had antibiotics been given before delivery. There were six multiple pregnancies associated with seven deaths. We were not able to detect any change in prevalence over the 16 year period.

\section{Discussion}

Our data give a minimum incidence of 0.8 deaths per 10000 live births due to early onset group B streptococcal infection, a rate very similar to that predicted for the United States ${ }^{3}$ and comparable with that in other parts of Europe and Australia. Figure 1 shows mean death rates from early onset group B streptococcal infection in other large studies carried out over the past 20 years in Britain, ${ }^{79}$ other parts of Europe ${ }^{10-18}$ Australasia ${ }^{19-22}$ and the United States. ${ }^{23-25}$ Several studies defined early onset cases as those presenting in the first week. ${ }^{2710-1214151823}$ If this criterion had been used in this study the incidence would have been almost unchanged as there were only two additional deaths presenting between 2 and 6 days of age.

The incidence in this study is similar to the rate found during the 1978-9 Public Health Laboratory Service study ${ }^{7}$ even though this was the study that caused The Lancet to imply that early neonatal infection was less common than in the United States, ${ }^{26}{ }^{27}$ a misperception now reflected in many United Kingdom textbooks. Earlier commentators may have made erroneous comparisons between the Public Health Laboratory Service data which were population based, and United States studies of the same era $^{28}$ which were largely hospital based. Studies reporting data from tertiary referral centres are subject to several biases, and frequently live birth denominator data are not accurate. We have, where possible, contacted and confirmed with the original authors both the enumerator and denominator data for other large studies in our figure. Figure 1 illustrates the difference between population and hospital based studies.

Although this study is retrospective, death from infection, as opposed to infection per se, is relatively easily defined and permits good comparison with other studies. Many units in the United Kingdom are currently participating in a large Medical Research Council funded ORACLE trial (preterm antibiotic uncertainty study) and do not therefore have written policies for intrapartum antibiotics similar to that proposed by the Centers for Disease Control and Prevention ${ }^{3}$ in the United States; and in this region only two of 14 obstetric units have a written policy for certain group B streptococcal risk groups. Our study strongly suggests that a decision not to adopt a policy of intrapartum antibiotic prophylaxis for certain risk groups in the United Kingdom (similar to the strategies now widely adopted in the United States and parts of Australia) cannot be based on an assumption that the incidence of lethal early onset infection is different.

In the recent annotation on this subject ${ }^{29}$ it was suggested that "...when the incidence of early onset group B streptococcal infection is low ... expensive preventative measures may not be justified." This may well be correct, but should be seen in context. Our study, the Public Health Laboratory Study, ${ }^{7}$ and the Oxford study $^{9}$ (albeit with wide confidence intervals) all estimate the incidence of death to be about 0.1 per 1000 live births, a figure not dissimilar to the rate of fatal intracerebral bleeding potentially prevented by vitamin $\mathrm{K}$ prophylaxis. Controlled studies of the incidence of infection and relative risk factors for this country are urgently required to determine the optimum strategy for reducing the incidence of perinatal group B streptococcal disease.

We are extremely grateful to the clinicians and district convenors without whose long term support of the Regional Perinatal Mortality Survey this retrospective review would not have been made possible, and to all the consultant pathologists in the region for all the supplementary information they made region for
available. 
1 Stoll BJ. The global impact of neonatal infection. Clin Perinatol 1997;24:1-21.

2 Zangwill KM, Schuch A, Wenger JD Group B streptococcal disease in the United States, 1990: report from a multistate active surveillance system. Morbid Mortal Week Rep 1992;41:25-32.

3 Prevention of perinatal group B streptococcal disease: a public health perspective. Centers for Disease Control and Prevention. Morbid Mortal Weekly Rep 1996;45(RR-7) :1-24.

4 ACOG committee opinion. Prevention of early-onset group B streptococcal disease in newborns. Number 173--June 1996. Committee on Obstetric Practice. American College of Obstetrics and Gynecologists. Int $\mathcal{F}$ Gynaecol Obstet 1996;54:197-205.

5 Revised guidelines for prevention of early-onset group B streptococcal (GBS) infection. American Academy of Pediatrics Committee on Infectious Diseases and Co Pediatrics Committee on Infectious Diseases and Com-

6 Jeffery HE, Moses Lahra M. Eight-year outcome of universal screening and intrapartum antibiotics for maternal sal screening and intrapartum antibio

7 Mayon-White RT. The incidence of neonatal group $B$ streptococcal disease in Britain. VIIIth International Symposium on Streptococci and Streptococcal Diseases. Chertsey, Surrey: Reedbooks Ltd, 1981:305-6.

8 Perinatal mortality: a continuing collaborative regional survey. $B M F$ 1984;288:1717-20.

9 Moses LM, Heath PT, Wilkinson AR, Jeffery HE, Isaacs D. Early onset group B streptococcal neonatal infection in Oxford 1985-96. Arch Dis Child 1998;79:F148-9.

10 Carstensen H, Henrichsen J, Jepsen OB. A national survey of severe group B streptococcal infections in neonates and young infants in Denmark, 1978-83. Acta Paediatr Scand 1985;74:934-41.

11 Kristensen B, Schonheyder HC. A 13-year survey of bacteraemia due to beta-haemolytic streptococci in a Danish county. F Med Microbiol 1995;43:63-7.

12 Sjoberg I, Hakansson S, Eriksson A, Schollin J, Stjernstedt B, Tessin I. Incidence of early onset group B streptococcal
septicemia in Sweden 1973 to 1985 . Eur 7 Clin Microbiol Infect Dis 1990;9:276-8.

13 Kallman J, Kihlstrom E, Sjoberg L, Schollin J. Increase of staphylococci in neonatal septicaemia: a fourteen-year study. Acta Paediatr 1997;86:533-8.

14 Vesikari T, Janas M, Gronroos P, et al. Neonatal septicaemia. Arch Dis Child 1985;60:542-6.

15 Vesikari T, Isolauri E, Tuppurainen $\mathrm{N}$, et al. Neonatal septicaemia in Finland 1981-85. Predominance of group B streptococcal infections with very early onset. Acta Paediatr Scand 1989;78:44-50.
16 Lejeune C, Jaby-Sergent MP, Floch-Tudal C. Early, severe, neonatal infections due to streptococcus group B. Multicenter retrospective study on the incidence and ris factors. F Gynecol Obstet Biol Reprod 1995;24:644-50.

17 Clemente Yago F, Tapia Collados C, Escriva Tomas P, Rubio Soriano A, Garcia Martinez R, Jimenez Cobo Neonatal septicemia: incidence and risk factors. An Esp Pediatr 1992;37:481-3.

18 Hervas JA, Alomar A, Salva F, Reina J, Benedi VJ. Neonatal sepsis and meningitis in Mallorca, Spain, 1977-1991. Clin Infect Dis 1993;16:719-24.

19 Garland SM, Fliegner JR. Group B streptococcus (GBS) and neonatal infections: the case for intrapartum chemoprophylaxis. Aust $N \quad Z \quad \mathcal{F}$ Obstet Gynaecol 1991;31:119-22.

20 Sanghvi KP, Tudehope DI. Neonatal bacterial sepsis in a neonatal intensive care unit: a 5 year analysis. $\mathcal{F}$ Paediatr Child Health 1996;32:333-8.

21 Early-onset group B streptococcal infections in Aboriginal and non-Aboriginal infants. Australasian Study Group for Neonatal Infections. Med f A ust 1995;163:302-6.

22 Maxwell FC, Bourchier D. Neonatal septicaemia: a changing picture? NZ Med f 1991;104:446-7.

23 Schuchat A, Oxtoby M, Cochi S, et al. Population-based risk factors for neonatal group B streptococcal disease: results of a cohort study in metropolitan Atlanta. F Infect Dis 1990;162:672-7.

24 Philip AG. The changing face of neonatal infection: experience at a regional medical center. Pediatr Infect Dis $\mathcal{F}$ 1994;13:1098-102.

25 Schuchat A, Deaver-Robinson K, Plikaytis BD, Zangwill KM, Mohle-Boetani J, Wenger JD. Multistate case-control study of maternal risk factors for neonatal group B streptococcal disease. The Active Surveillance Study Group. Pediatr Infect Dis ₹ 1994;13:623-9.

26 Anonymous. Neonatal infection with group B streptococci [editorial]. Lancet 1981;ii:181-2.

27 Anonymous. Prevention of early-onset group B streptococcal infection in the newborn [editorial]. Lancet 1984;i: $1056-8$

28 Pyati SP, Pildes RS, Ramamurthy RS, Jacobs N. Decreasing mortality in neonates with early-onset group B streptococcal infection: reality or artifact. F Pediatr 1981;98:625-7.

29 Isaacs D. Prevention of early onset group B streptococcal infection:screen, treat, or observe. Arch Dis Child 1998;79:F81-2 